\title{
ON THE RHINENCEPHALON OF DELPHINUS DELPHIS, L.
}

\author{
WILLIAM H, F. ADDISON \\ From the Neurological Institute, Frankfurt-am-Main, and the Anatomical Labora- \\ tory, University of Pennsylvania, Philadelphia \\ FIFTEEN FIGURES
}

CONTENTS

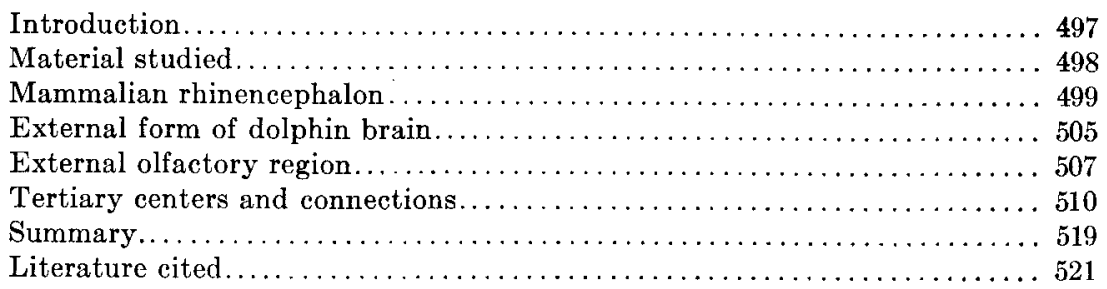

\section{INTRODUCTION}

The brain of the common dolphin is characterized by the entire absence of the olfactory tracts and bulbs, and hence the dolphin is completely anosmatic. It was in 1878 , that Broca first applied the terms osmatic and anosmatic to the Mammalia as a means of classifying them according to the relative state of development of their entire olfactory apparatus. In the group of anosmatic Mammalia he placed the Primates, Cetacea, and Carnivora pinnipedia; leaving all others in the osmatic group. Later Turner ('90) made the subdivisions macrosmatic, microsmatic and anosmatic. In the macrosmatic forms he included the Ungulata proper, the Carnivora fissipedia, and, indeed, the majority of mammals. In the group of microsmatics, or those having the olfactory system relatively feeble, he placed the Carnivora pinnipedia, the whalebone whales, apes and man; while under the anosmatic group were placed the dolphins, and 
with some uncertainty, due to lack of definite information, the toothed whales in general.

As is well known, the Cetacea, as a result of their conformation to an aquatic mode of life, have undergone many changes in their structural peculiarities, but in no system perhaps are these changes more striking than in the organs concerned with olfaction. In the adult animals, the turbinates are relatively much reduced in size, the cribriform plate of the ethmoid is imperforate or may have only a single pair of openings, while the olfactory bulbs and tracts are represented by slight remnants or disappear entirely. The whole apparatus for the sense of smell is much reduced, thus rendering very appropriate the terms microsmatic and anosmatic to the different members of this order. Whether the anosmatics, like other mammals, have olfactory tracts and bulbs during fetal life, has not been carefully studied but it is certain that they lack them entirely in the mature animals. Thus, as stated above, there is not the slightest trace of these structures in the adult dolphin's brain.

Because of the disappearance of these external portions of the rhinencephalon, it has been interesting to study the more centrally placed parts of the olfactory mechanism, in order to see the extent of their regression. The brain of the dolphin has been studied from the same point of view by Broca ('79) and Zuckerkandl ('87). Their observations, however, were restricted for the most part to the external form and gross relations.

\section{MATERIAL STUDIED}

At the Frankfurt Neurological Institute, conducted under the direction of Professor Edinger, to whom I am greatly indebted, during the summer of 1914 , I had the opportunity of examining thin sections of the brain of an adult dolphin. The sections were cut serially, and every third section stained by Weigert's myelin method. Each section was mounted on a separate plate of glass and covered with gelatine by the method worked out in the Frankfurt laboratory. In addition, five hemispheres, preserved in formalin, were available for gross study. These brains were 
given to the institute by H. I. H. Prince Alexander of Oldenburg, and came from the Black Sea in the Caucasus. The sections were studied for the most part with a hand lens, or the unaided eye, and the use of the compound microscope was resorted to, only for finer details. The drawings of the sections were made with the aid of the Edinger projection drawing apparatus.

\section{MAMMALIAN RHINENCEPHALON}

The several parts of the brain which are generally considered to belong to the olfactory mechanism may first be mentioned. It is agreed that the bulbus olfactorius, the tractus clfactorius coming from it, and the region of the lobus olfactorius where this tract ends, are the most certain parts. Since the studies of Broca and of Zuckerkandl, the hippocampus has also been included as part of the olfactory centers, and guided by the work of Edinger, Elliot Smith, Zuckerkandl and Ramón y Cajal, we now consider this as a tertiary center for olfactory receptions.

For a long time the tuberculum olfactorium (lobus parolfactorius), lying mesial to the lobus olfactorius, was also considered to belong to the same general olfactory apparatus, but latterly, especially through the work of Edinger, this has become very doubtful. He looks upon it as the center for a special sense, which he has termed the 'oral sense,' and which is especially large in those animals which have highly developed sense perceptions in the snout region.

In addition to the fibers joining the lobus pyriformis to the hippocampus (Edinger '11, p. 380) there arise from the olfactory and parolfactory lobes, several other bundles which join these structures to the tertiary centers. (1) The tractus olfacto-hippocampanicus is strongly developed in macrosmatic animals, especially where the corpus callosum is small or lacking, but it dwindles in man to the stria longitudinalis Lancisii. (2) The fasciculi parolfacto-hippocampo-septales, first described by Zuckerkandl ('87), pass into the septum pellucidum, and unite at the dorsal and caudal end of this structure with the fornix fibers. After this union they go back together and enter the cortex of the hippocampus. According to Edinger this is a very primitive 
connection. (3) The taenia semicircularis, also, arises somewhere in the neighborhood of the base of the corpus striatum, probably mainly from the lobus parolfactorius, follows the boundary between the thalamus and the nucleus caudatus and ends, curving downwards and forwards, in the nucleus amygdalae. (4) The stria medullaris thalami (taenia thalami) too, ending in the median side of the thalamus in the ganglion habenulae, is usually thought to be part of the olfactory structures. Edinger's work, however, has made it very probable that it belongs not, or at least not only, to the olfactory apparatus, but to what he calls the parolfactory apparatus, whose center lies in the lobus parolfactorius.

The anterior commissure (commissura ventralis) is generally considered as the most important commissure of the olfactory apparatus. In its frontal bundle it contains fibers uniting the two olfactory bulbs, while its more caudal and dorsal bundle connects cortical parts which stand in some way related to the olfactory apparatus, viz., lobus pyriformis and subiculum. Also in many lower mammals where the hippocampus lies dorsad of the brain stem, and is not yet pushed back by the corpus callosum, there is a third bundle in the anterior commissure. Since Owen's work, and, more recently, by that of Elliot Smith and Symington, we know that this third part consists of a thick strand of fibers which runs to the dorsally placed hippocampus. Thus while in most mammals the commissura anterior has the form of a double horse-shoe lying in a horizontal plane, as is well shown in figure 290, page 386, of Edinger's Vorlesungen ('11), in monotremes and marsupials there is a third horse-shoe standing upright upon the connection of the other two, uniting the aforementioned dorsal cortical parts.

The other commissure of the olfactory apparatus is the psalterium (commissura dorsalis), which is made up of crossing fibers between the two hippocampi themselves.

Other structures which may be partly connected with this system are the claustrum, lying outside of the nucleus lentiformis and under the cortex; and (with more certainty in the lower vertebrates) the corpus striatum. Whether these should be included in mammals is quite doubtful. 
According to Edinger and Wallenberg, there is a tract, the basal olfactory bundle, running from the olfactory bulbs and peduncles in a direct path to the region of the corpora mamillaria, and part of the fibers may go even to the ganglion interpedunculare.

These parts of the mammalian brain, which are concerned in the conduction of olfactory and associated impulses vary greatly in their form and position, and in their size relative to surrounding structures, in the different species. This variation depends upon two main circumstances. The first is the degree of development of the olfactory mechanism itself. The second is the position that the animal has attained in the scale of intelligence, this being connected, usually, with the size of the neopallium. In the higher forms, there is increasing development of the neopallium, and consequent overshadowing of the primitive parts.

As the lower orders of mammals possess, in general, a welldeveloped olfactory sense, without any great development of the neopallium, they present a more easily understood olfactory mechanism. The study of such forms in recent years has made clear the fundamental olfactory portions of the brain. With the increasing development of the neopallium and associated structures (frontal and temporal lobes, corpus callosum) and often the decreasing importance of the olfactory structures, a much more intricate arrangement has been arrived at, as in the human brain. An intermediate condition, where there is a medium development, both of the olfactory apparatis and of the neopallium, is found in many animals, such as terrestrial Carnivora and the ungulates.

These three grades are illustrated in figures 1, 2, and 3 , in the drawings of the base of the brain of the rabbit, calf and man. These demonstrate the external differences between macrosmatic and microsmatic forms, and the variation which may exist in the relative extent of the rhinencephalon within the macrosmatics.

Partly perhaps as the result of this morphological variability, one often finds a diversity of meaning attached to one term, as used by the various investigators working on comparative 
and human brain anatomy. In the description of the figures as given below, I have followed elosely the nomenclature used by Beccari ('10, '11), who studied in Edinger's laboratory.

The regio olfactoria (olfactory lobe) is seen in figures 1,2 and 3 , to consist of bulbus olfactorius (which receives the processes

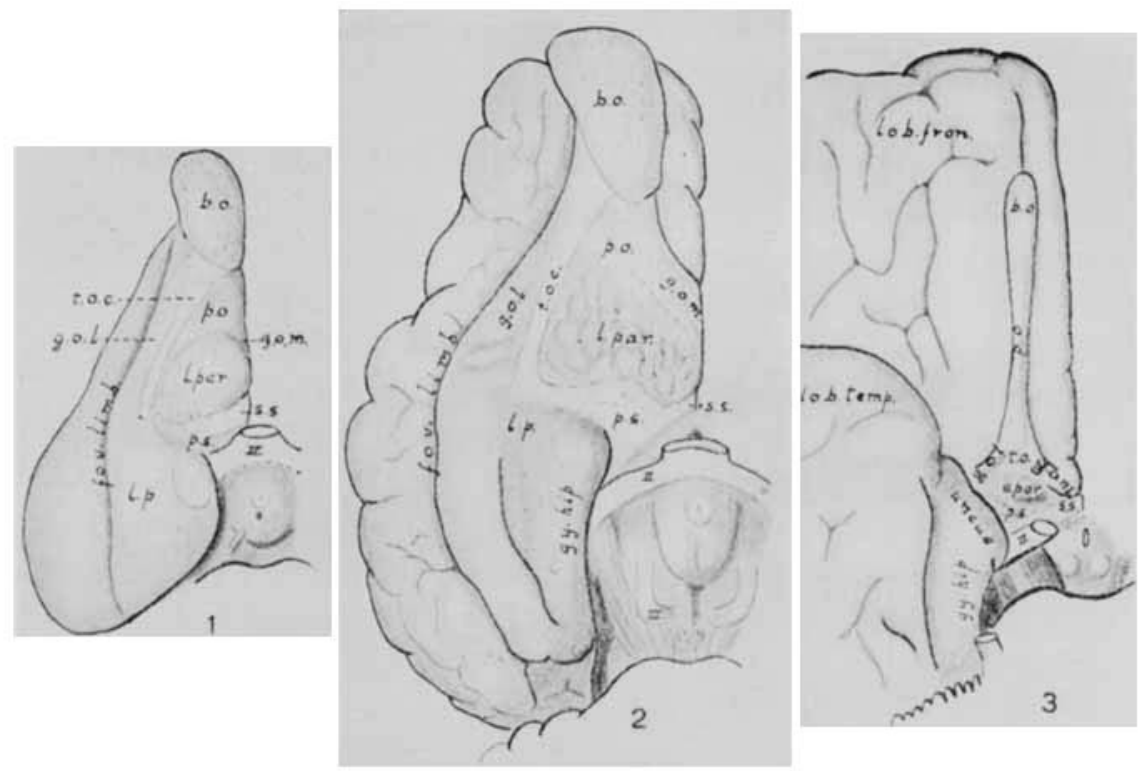

Fig. 1 Base of brain of rabbit (Lepus euniculus), a macrosmatic animal with small pallium. Shows great development of olfactory and parolfactory structures. These extend the entire length of the brain, and include all parts designated by letters, mesial to the fovea limbica. $\times 1 \frac{1}{2}$.

Fig. 2 Base of brain of calf (Bos taurus), a moderately macrosmatic animal, with increased size of neopallium. The parts of the cerebrum mesial to the fovea limbica, and anterior to and including the region marked $l . p$., belong to the palaeencephalon, and are all olfactory and parolfactory structures. The remaining parts of the cerebrum shown are neencephalic. The lobus pyriformis is much reduced and ends by merging with the uncus of the gyrus hipposampus. The inereased size of the neopallium is better seen from the lateral aspect. $\times \frac{3}{4}$.

Fig. 3 Portion of base of adult human brain, microsmatie and having great development of neopallium. The olfactory bulb is small, and the peduncle is much elongated. The eminentia parolfactoria is small, or may be nearly wanting. The remains of the lobus pyriformis are within the vallecula Sylvii, and have become overgrown by and fused with the temporal lobe. The extent of the lobus pyriformis is more distinctly seen in the brain of the 5-month fetus. $\times \frac{3}{4}$. 
of the olfactory cells), pedunculus olfactorius, tractus olfactocorticalis (figs. 1 and 2), medial and lateral olfactory gyri, and lobus pyriformis (figs. 1 and 2). The regio parolfactoria comprises the lobus parolfactorius (in man, preferably called eminentia parolfactoria), the planum septale and stylus septi. The planum septale is Beccari's term for the anterior perforated space of human anatomy, while the stylus septi comprises two structures-the diagonal band of Broca (bandelette diagonale), and the gyrus subcallosus of Zuckerkandl. In the microsmatic human brain, having great pallial development, the bulbus is ex.tremely

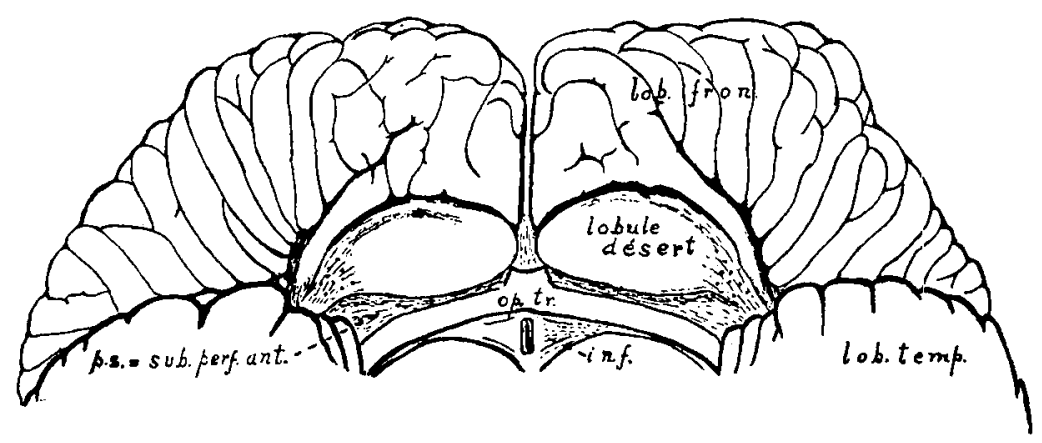

Fig. 4 Anterior portion of base of brain of dolphin, anosmatic and with large and highly convoluted pallium. Shows lack of external olfactory structures and presence of a conspicuous oval field on each side, lobule desert, where the cortex is lacking, and the head of the corpus striatum comes to the surface. Very distinet furrows marked off the lobule desert in this brain. $\times \frac{\frac{4}{5}}{\text {. }}$.

\section{ABBREVIATIONS}

FIGORES 1 TO 4

b.o., olfactory bulb

e.par., eminentia parolfactoria (fig. 3)

fov.limb., fovea limbica, or ectorhinal

fissure

g.o.l., lateral olfactory gyrus

g.o.m., mesial olfactory gyrus

gy.hip., gyrus hippocampus

inf., infundibulum

$l . p .$, lobus pyriformis

l.par., lobus parolfactorius (= emin-

entia parolfactoria, fig. 3 ) lob.fron., frontal lobe

lob.temp., temporal lobe

lobule désert, or désert olfactif, Broca $o p . t r$. , optic tracts

p.o., pedunculus olfactorius (or olfactory tract, fig. 3)

p.s:, planum septale (piano settale)

or anterior perforated space

s.s., stylus septi

t.o.c., tractus olfacto-corticalis 
small, and the olfactory peduncle or tract narrow but very elongated. As Elliot Smith ('02) points out, the length of the peduncle in the human brain is probably brought about by the bulb being anchored in a fixed position by the olfactory nerves coming through the cribriform plate, and by the increase in size of the frontal lobe, which moves backward the position of the attachment of the peduncle to the base of the brain. These two circumstances result in the great attenuation of the peduncle.

The lobus parolfactorius in the calf (fig. 2) shows an appearance typical for many macrosmatic animals, as found by Beccari ('10). In man this region is so reduced as to make the term eminentia parolfactoria more appropriate. According to Beccari ('11) who investigated a series of fifty human brains, in twenty-five per cent $(25 \%)$ it was well developed, in fifty per cent $(50 \%)$ weakly developed, and in twenty-five per cent $(25 \%)$ was lacking. This region has been the subject of recent controversy. Edinger has wished to separate it from the olfactory system, and asserts that but few olfactory fibers (e.g. of tractus olfacto-corticalis) penetrate it, but that it receives tracts from the region where the trigeminus ends. The lobus parolfactorius he would designate as the center for impulses, coming by way of the fifth nerve, from specialized sensory structures in the snout region. Its variation in size in the different species he would correlate not with the olfactory sense but with the 'oral sense,' the height of development of which depends upon the size and character of the innervated area at the oral pole. Elliot Smith, using the brain of Orycteropus, contended that many fibers of the olfactory tracts could be seen covering and entering this lobe and hence that it should still be called tuberculum olfactorium. Later Edinger studied sections of the brain of Orycteropus and found that this lobe received none or very few of the olfactory fibers. The region was examined carefully by Beccari ('10, '11) in a series of mammals and in man, and he agrees with Edinger that it is a special field, but does not think the proof quite sufficient that it has to do with an oral sense. He found that it has well developed connections with the hippocampus, nucleus amygdalae, and ganglion habenulae, slighter 
with the regio olfactoria, and perhaps some with the nucleus of the fifth nerve. Bindewald ('13) studying this region in the elephant, found it very large as one might expect in an animal with such a large and sensitive snout apparatus as the trunk. Thus there is no final agreement as to its status at the present time.

The planum septale, or anterior perforated space of human anatomy, is a region where normally the central ganglia come to the surface without any cortical covering. In the dolphin (fig. 4) we will see that there is a much increased area of central ganglion exposed.

The extent of the lobus pyriformis varies greatly in different orders, but in all it is a palaeencephalic structure. In lower mammals it comprises the entire region mesial to the fovea limbica or rhinal fissure, but in higher mammals neopallial structures also develop in this area. In this view of the adult human brain (fig. 3), practically nothing is seen of the much diminished lobus pyriformis within the vallecula Sylvii, but in the 5-month fetus brain it is easily recognizable as an acutely bent band running laterad of the planum septale, and ending caudally in the temporal lobe (see Villiger-Piersol, 1912, p. 26, fig. 26). In the adult this caudal portion becomes fused with part of the temporal lobe, although the diminutive gyri semilunaris and ambiens still show as landmarks indicating its limit, and the slight incisura temporalis at the margin of the uncus persists as the representative of the primitive rhinal fissure.

\section{EXTERNAL FORM OF DOLPHIN BRAIN}

The cetacean brain is wide and blunt, and presents an appearance quite different in some respects from that of all other mammals (figs. 4 and 6). The frontal part does not taper towards the nose, but curves round in a strange way, so that what is usually the most frontal point has to be looked for at the base of the brain, not far frontad of the chiasma. Thus the whole organ is not egg-like in form but is more globular, and it is quite possible that this shape is the result of the retrogression of its olfactory 
system. This was the opinion of Tiedemann ('26) and also of Elliot Smith ('02), but another explanation may be offered.

The fact that, in the process of adjustment of the organism to the new environment, the external respiratory opening has come to open at the dorsal surface of the head in these animals, instead of at the extremity of the snout, may also be a factor in limiting the growth of the brain anteriorly. When one examines the cranium, the air-chambers are seen to descend directly in front of the cranial cavity. In an animal which must come to the surface to breathe every few seconds, it is evidently convenient to have the air-openings on the dorsal surface of the head, and equally desirable that the pathway to the pharynx and larynx should be most direct, and this is certainly helped by the shortness anteriorly of the brain-box. Thus there may be a correlation between the change in position and direction in the airpassages, and the peculiar shape of the brain, entirely apart from the presence or absence of olfactory structures in the brain.

In the Mystacoceti (baleen whales) there is a diminutive olfactory bulb and peduncle, but in some of the Odontoceti (toothed whales) these structures are wanting. This is the case in the adult dolphin, where there is not the slightest trace of olfactory nerves, even in microscopic sections. In Globiocephalus melas there is reported to be complete absence of external olfactory structures in the brain by Pettit ('05), and this is the condition, too, in Beluga (Delphinapterus) according to Kükenthal and Ziehen ('89), who state, also, that there is a slight development of the olfactory structures in the embryo. In Tursiops truncatus, specimens of which lived for some time in the New York Aquarium, no olfactory bulbs and tracts were seen when the brains were removed in the laboratory of Prof. G. S. Huntington. Although Delphinus is destitute of olfactory nerves, others of the family Delphinidae possess them. Thus, in Phocaena (Edinger '11) there is a microscopic trace of these structures, and in Hyperoodon of the family Platanistidae there are also small olfactory nerves (Kükenthal and Ziehen, '89). Thus among the toothed whales, some have small olfactory structures while others have none at all. 
Early observers who pictured cetacean brains which exhibited absence of olfactory structures were Tiedemann ('26) and Stannius ('46).

The outside form of these cetacean brains is known from the works of several writers, the furrows especially having been discussed by Kükenthal and Ziehen ('89) and Elliot Smith ('02), among others. But sections have only twice been studied. In 1905, at the Baden. Congress, Jelgersma read a paper" on the results of his study of the brain of Phocaena, but this has never been published except by title. And also we have a very good description of the brain-stem of Delphinus by Hatschek and Schlesinger ('02), in which, however, the study of the forebrain and olfactory apparatus was outside of the special plan of their work.

\section{EXTERNAL OLFACTORY REGION}

The ventral surface of the dolphin's brain (figs. 4 and 5) gives at first the impression that, though the olfactory tract and lobe are entirely absent, the lobus parolfactorius is still present in large size. One sees just in front of the chiasma, on either side, a large, somewhat oval, convex, protruding area, quite distinct, in appearance from the substance of the frontal lobe. Broca, who was surprised to find no convolutions there, called it 'lobule désert.' This lies at a place where one finds in other mammals the lobus parolfactorius, and indeed, like this, it has behind it a typical substantia perforata anterior, as already described by Kükenthal and Ziehen. Frontally it is separated from the cortex of the frontal lobe by a depression which shows considerable variation in extent and depth in the several brains examined. In one of the brains (fig. 4), it was very deep and showed as a continuous furrow. In another (fig. $5 \mathrm{~A}$ ) the depression was quite shallow and as a result the area did not appear so bulging. In a third, depicted in figure $5 \mathrm{~B}$, there was a distinct furrow mesially, but this became less marked laterally.

Laterally this area extends as a narrow grayish band, which disappears, getting narrower and narrower, in about the region where the nucleus amygdalae lies. This narrow grayish band 
occupies the position which in macrosmatic mammals is occupied by the large olfactory lobe, and may be here the remnants of the atrophied olfactory lobe.

Stained sections show that the main part of the bulging out of Broca's 'lobule désert' is made by the head of the nucleus caudatus which is at this place curved round to the ventral surface
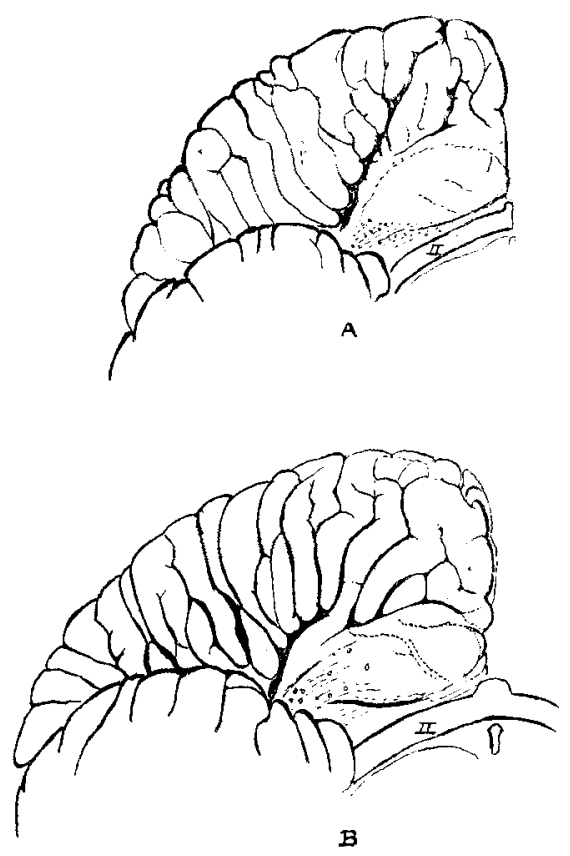

Fig. 5 Basal view of anterior portions of hemispheres of brains of two other dolphins, to show variations in depth of the depressions surrounding the lobule désert. In neither are the furrows so marked as in the brain shown in figure 4 . In $A$, the furrow frontad of the lobule desert is very shallow, while in $B$, it shows as a distinct depression mesially, but nearly disappears laterally. $\times \frac{4}{5}$.

of the brain. But the protuberance is covered at its ventral surface by two sorts of cortex. Frontally and mesially there is a continuation of the typical frontal cortex, but caudally and everywhere laterally there is another cortex-like covering. Separating the one from the other are one or two shallow furrows, as shown in the figure of section 153 (fig. 11). The gray sukstance of the frontal cortex here shows the same general structure as 
elsewhere. The other part of the cortical covering, divided from the frontal cortex by one or two shallow furrows, is made up of gray matter covered by a medullated nerve layer of very fine fibers. This layer of nerve fibers is pushed down here and there into little processes, which project into the underlying gray substance and thus give a somewhat undulated appearance to the outline of the latter.

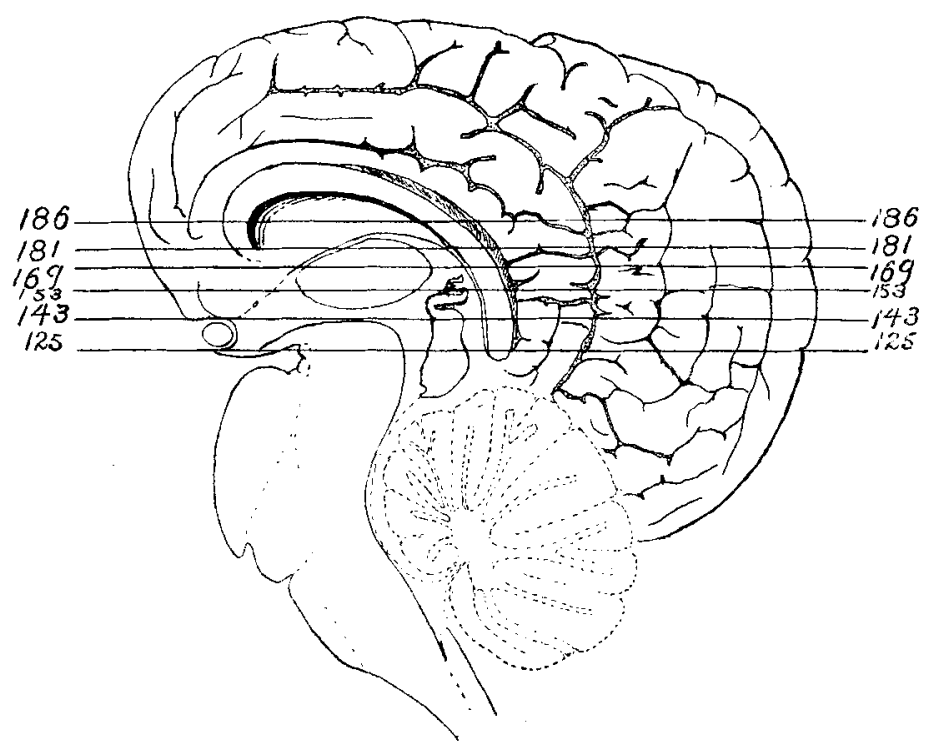

Fig. 6 Median sagittal section of brain of adult dolphin. The numbered lines indicate the planes and positions of the sections which have been drawn. In comparison with brains of macrosmatic animals, it shows a rounded form in the frontal region, and not a tapering form. The floor of the central canal of the brain recurves, as it descends from the aqueduct of Sylvius to the posterior wall of the infundibulum. The corpus callosum is large and well-arched. The anterior commissure is very small. $\times \frac{4}{5}$.

It is more than probable that this slightly convoluted corticallike plate, which lies just where we are accustomed to see the more distinctly convoluted cortex of the lobus parolfactorius, constitutes the last remnants of this formation.

Laterally (fig. 11) the medullated fibers are more numerous and more closely packed, so that the lateral aspect of the nucleus lentiformis is covered only by a relatively thin layer of grayish- 
white substance which has not the aspect of any definite cortexform. One is inclined to regard this part as being the last remnants of the olfactory lobe (fig. 11).

So one concludes that the main part of the bulging out of the base of the brain is made by the caput nuclei caudati. This is covered anteriorly and mesially by cortex of the frontal lobe. Laterally it is covered by the remnants of the olfactory lobe, and between these two is situated what remains of the better preserved, but still highly atrophied parolfactory cortex. It is also to be noted that the head of the striatum is separated from both varieties of cortical gray coverings by a thin layer of medullated nerve fibers.

More caudally (fig. 9), all three sorts of cortex-frontal, parolfactory and olfactory--disappear, leaving only a thin layer of white fibers over the otherwise naked protrusion of the caput nuclei caudati.

\section{TERTIARY CENTERS AND CONNECTIONS}

The hippocampus, as shown in its general relations (fig. 7) and in its detailed formation ( $\mathrm{fg} .8$ ), is an extremely small atrophic structure and it is with some diffidence that one attempts to homologize its parts with those of even the microsmatic type of

Fig. 7 Ventral portion of section 125, as shown in figure 6. The brain-stem is cut nearly transversely, showing mid-brain for the most part, but also, ventrally, a small portion of the infundibular region. Laterally and dorsally are portions of the temporal lobes (lob.temp.). Forming the mesial wall of the lateral ventricle (vent.lat.), are the fimbria (fim.) and atrophic hippocampus (hip.). A caudal part of the corpus callosum (corp.call.) is seen laterally, and beneath it the beginning of a crus fornicis (crus for.). The continuity between the fimbria and fornix does not show at the level of this section. $\times 2$.

$I I$, optic tract; $I I I$, third ventricle; aq., aqueduct of Sylvius; br.quad., brachium quadrigeminum; corp.mam.; region of corpus mamillare; lam.quad., quadrigeminal plate; lob.temp., temporal lobe; pes.ped., pes pedunculi; sub.nigra, substantia nigra.

Fig. 8 Dotailed drawing of hippocampal region of preceding figure, showing small size of the constituent structures. The atrophic hippocampus shows no elevation within the lateral ventricle. Groups of large colls represent the gyrus dentatus (gy.dent.). The fissura hippocampi $(f . h$.$) is extremely small, and below$ it, the region of the subiculum (subic.) is represented by the portion of the cortex containing fine medullated fibers. The nucleus amygdalae (nuc.amyg.) occupies a position in the floor of the lateral ventricle. $\times 5$.

fimb., fimbria; g.h., gyrus hippocarpi ; plexus, plexus in lateral ventricle. 

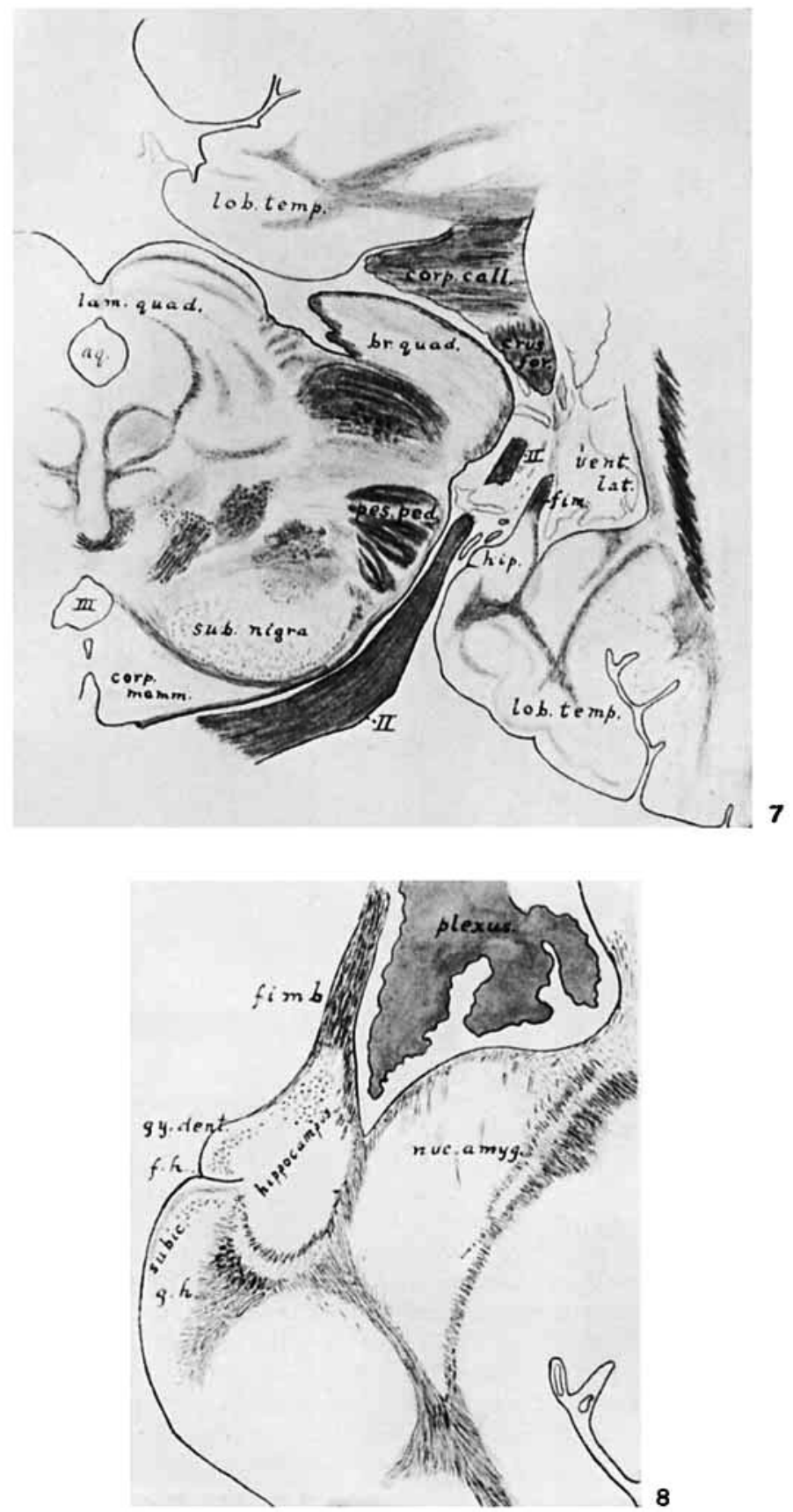

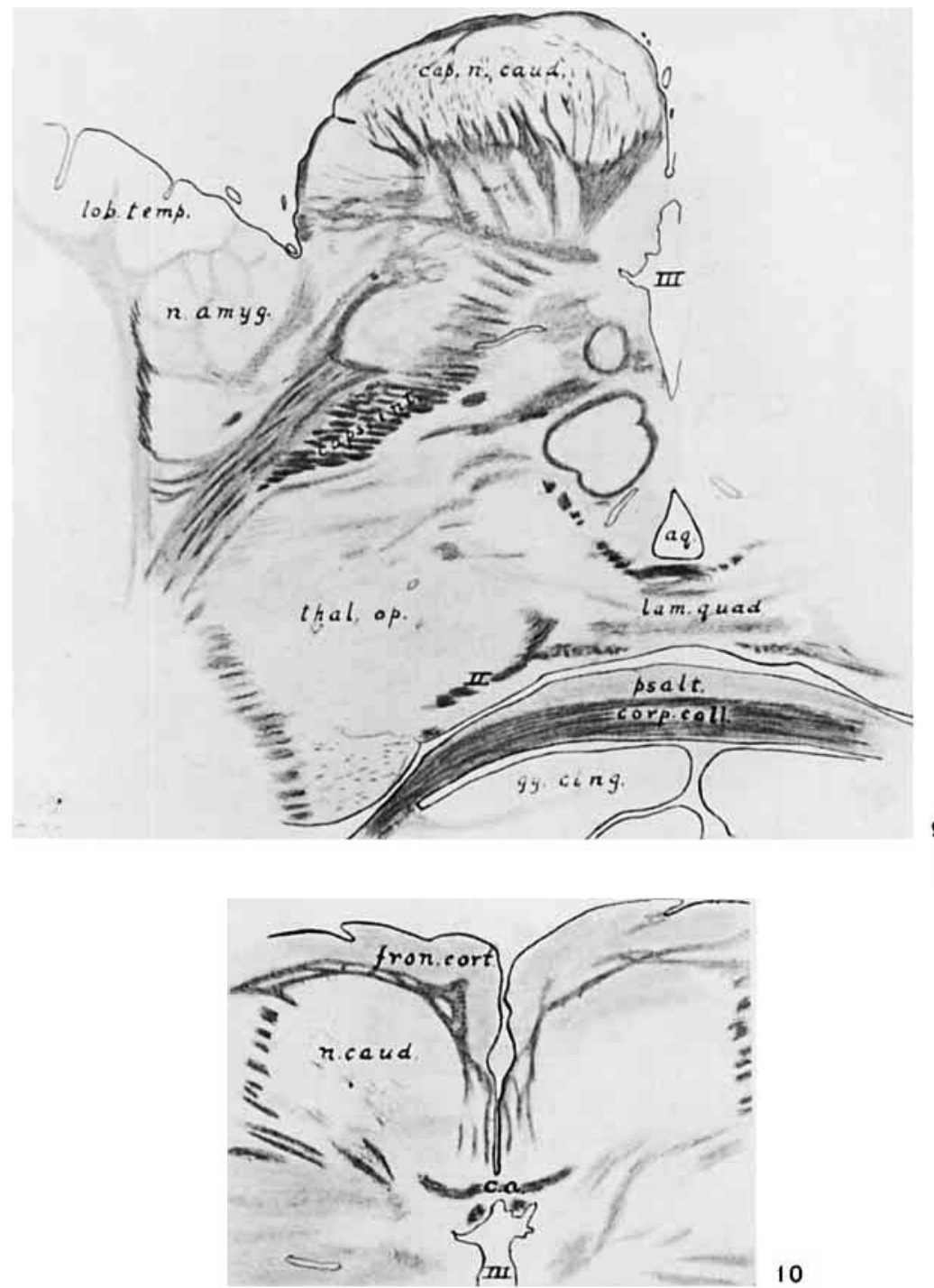

Fig. 9 Anterior portion of section 143, as shown in figure 6. Anteriorly is shown. the head of the caudate nucleus (cap.n.caud.) without any definite covering of cerebral cortex. In the temporal lobe (lob.temp.) is the nucleus amygdalae (n.amyg.), subdivided by crossing bundles of medullated fibers. Ventral to the corpus callosum (corp.call.) is a more lightly staining band of fibers, crossing the midline and constituting the psalterium (psalt.). The lateral regions of this band contain fibers which, not crossing, continue as the fornix fibers. $\times 2$.

$I I$, fibers of optic tract; $I I I$, third ventricle; $a q$., aqueduct of Sylvius; $g y$. cing., gyrus cinguli; lam.guad., quadrigeminal plate; thal. op., optic thalamus. 


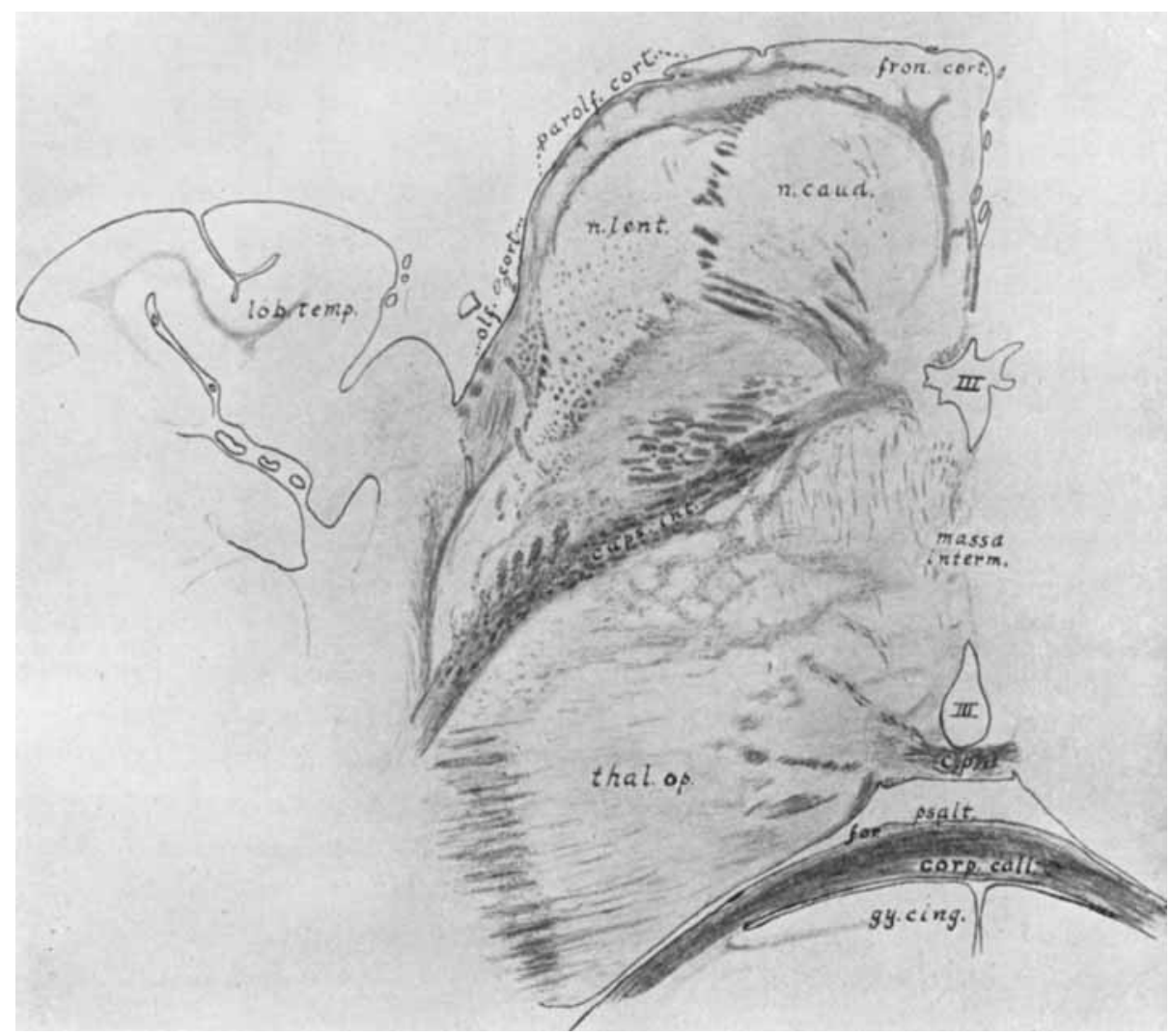

Fig. 10 Anterior portion of section 148. Shows the anterior commissure (c.a.) as a very narrow strand, disappearing laterally in the caudste nucleus (n.caud.). $\times 2$.

$I I I$, third ventricle; fron.cort., frontal cortex.

Fig. 11 Anterior portion of section 153, as shown in figure 6. Covering the caudate nucleus (n.caud.) is the typical frontal cortex, but covering the nucleus lentiformis (n.lent.) are two differently-appearing surface covering:s. The remains of the parolfactory cortex are shown by the presence of a superficial fiber layer, raised internally at intervals into little elevations. The region marked olf.cort., is taken to be region where the olfactory cortex existed formerly. Ventral to the corpus callosum (corp.call.) is a nore lightly staining band which contains fibers (1) of the psalterium (fibers crossing the midline), (2) of the fornix (for.) which are laterally placed, and (3) possibly of Zuckerkandl's bundle. $\times 2$.

$I I I$, third ventricle; caps.int., internal capsule; c.p., posterior commissure; gy.cing., gyrus cinguli ; lob.temp., temporal lobe; massa interm., massa intermedia; thal.op., optic thalamus. 
hippocampus. As there were no cell-preparations available for study, one can say nothing of the cell-layers, but one can readily appreciate the simple atypical form of the hippocampus, and its small size, which produces no apparent bulging into the ventricle. There is a very shallow fissura hippocampi, below which, in figure 8 , there is seen a small cortical area of the gyrus hippocampi, containing superficially a layer of fine medullated nerve fibers. This small cortical area is evidently the representative of the subiculum. There is no separated gyrus dentatus but above the fissura hippocampi are clusters of cells, which may represent the remnants of the gyrus dentatus. At the apex of the whole formation proceeds the fimbria in the typical way. Descriptions of the outer appearance of the hippocampus are to be found in Proca ('79), Zuckerkandl ('87) and Elliot Smith ('02).

The fimbria arises as a narrow elongated bundle from the margin of the hippocampus (figs. 7 and 8). Part of its fibers cross soon to the opposite side forming the hippocampal commissure, commissura dorsalis, or psalterium. This is shown as a rather broad band of fibers in figure 9, lying ventral to the corpus callosum, and consisting of fibers which stain more lightly than those of the corpus callosum. The psalterium appears so well developed that the possibility is suggested that it may contain other fibers in addition to the commissural hippocampal fibers. Perhaps fibers coming from the parolfactory cortex may cross here to reach the opposite hippocampus. A small portion of the psalterium is still apparent in section 153 (fig. 11). Other fibers of the fimbria proceed uncrossed as two flattened bands of the crura fornicis (section 169, fig. 12). These approach one another in the midline (section 181, fig. 13), where they form the body of the fornix. The general course of the fornix fibers is shown in figure 15, as reconstructed from several consecutive sagittal sections. The fornix fibers proceed under the corpus callosum until they enter the margin of the septum pellucidum (figs. 13 and 14). They traverse its curved outline and so are cut across twice in figure 13. They are seen again in figure 12, in the most anterior and ventral portion of the septum pellucidum. In our series of sections cut as shown in figure 6 , we were unable 
to follow these farther with certainty and so were of the opinion that all these fibers ended near this point, perhaps in the parolfactory cortex, and belonged to Zuckerkandl's bundle. But later Professor Edinger has been able to study a sagittal series, and finds that these fibers, or most of them, curve round in the

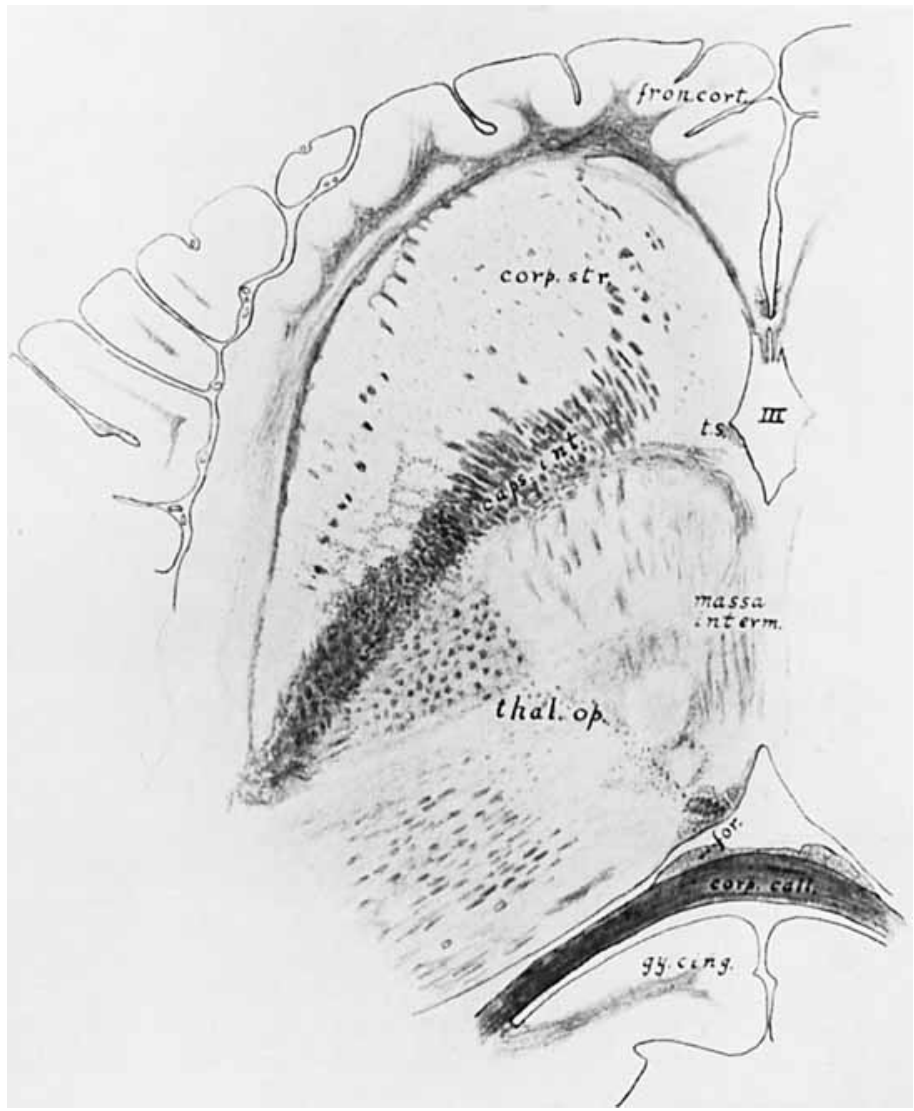

Fig. 12 Anterior portion of section 169 , as shown in figure 6 . The corpus striatum (corp.str.) is here covered by typical frontal cortex (fron.cort.). The taenia semicircularis (t.s.) is seen in the groove between optic thalamus (thal.op.) and corpus striatum (corp.str.). The massa intermedia (massa interm.) is cut across it greatest diameter. Ventral to the corpus callosum (corp.cali.) are seen the two strands of the fornix (for.). $\times 2$.

$I I I$, third ventricle; caps. int., internal capsule; gy.cing., gyrus cinguli. 


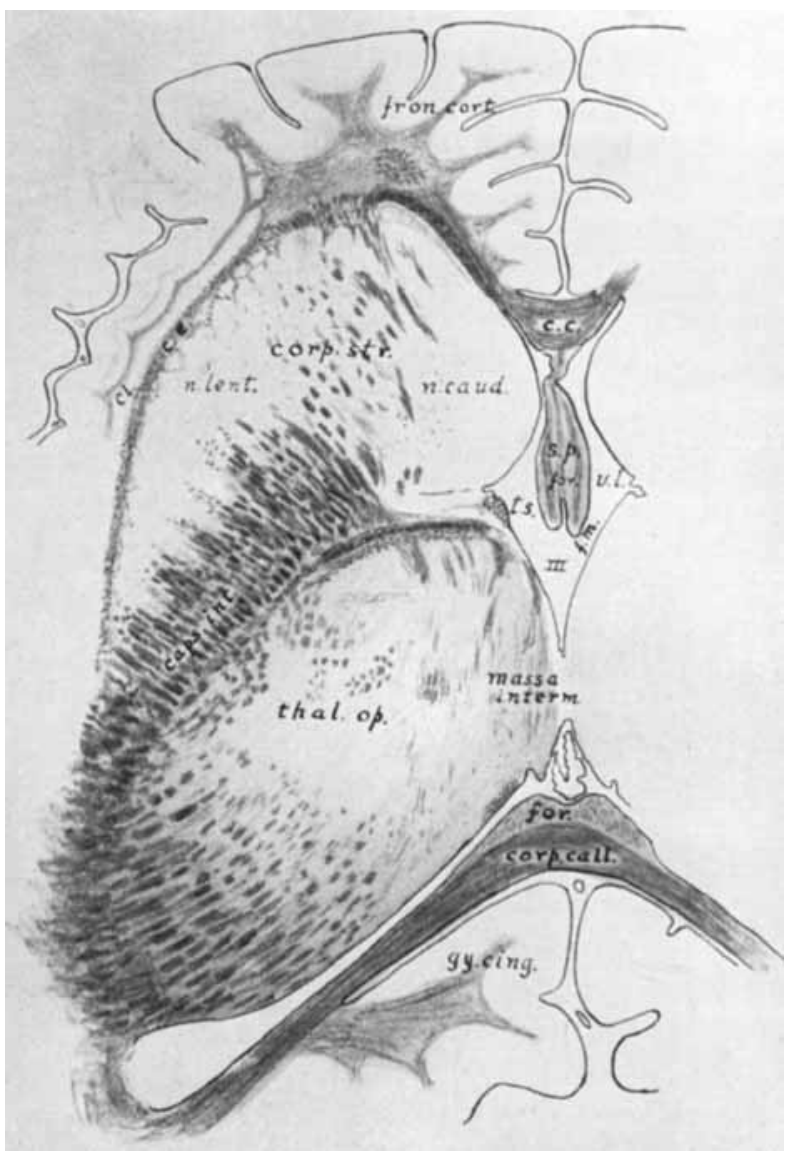

Fig.13 Anterior portion of section 181, as shown in figure 6. Shows the corpus callosum and fornix cut through twice. Beneath the more caudal part of the corpus callosum (corp.call.) the body of the fornix (for.) is seen as a flattened band. The fornix is again cut in the septum pellucidum (s.p.) near its free margin. The taenia semicircularis $(t . s$.$) is seen in the groove between caudate nu-$ cleus (n.caud.) and optic thalamus (thal.op.). The massa intermedia (massa interm.) is cut through its most frontal portion. $\times 2$.

c.e., external capsule; caps.int., internal capsule; cl., claustrum; corp.str., corpus striatum; f.m., foramen of Monro; fron.cort., frontal cortex; gy.cing., gyrus cinguli; n.lent., nucleus lentiformis; v.l., lateral ventricle. 


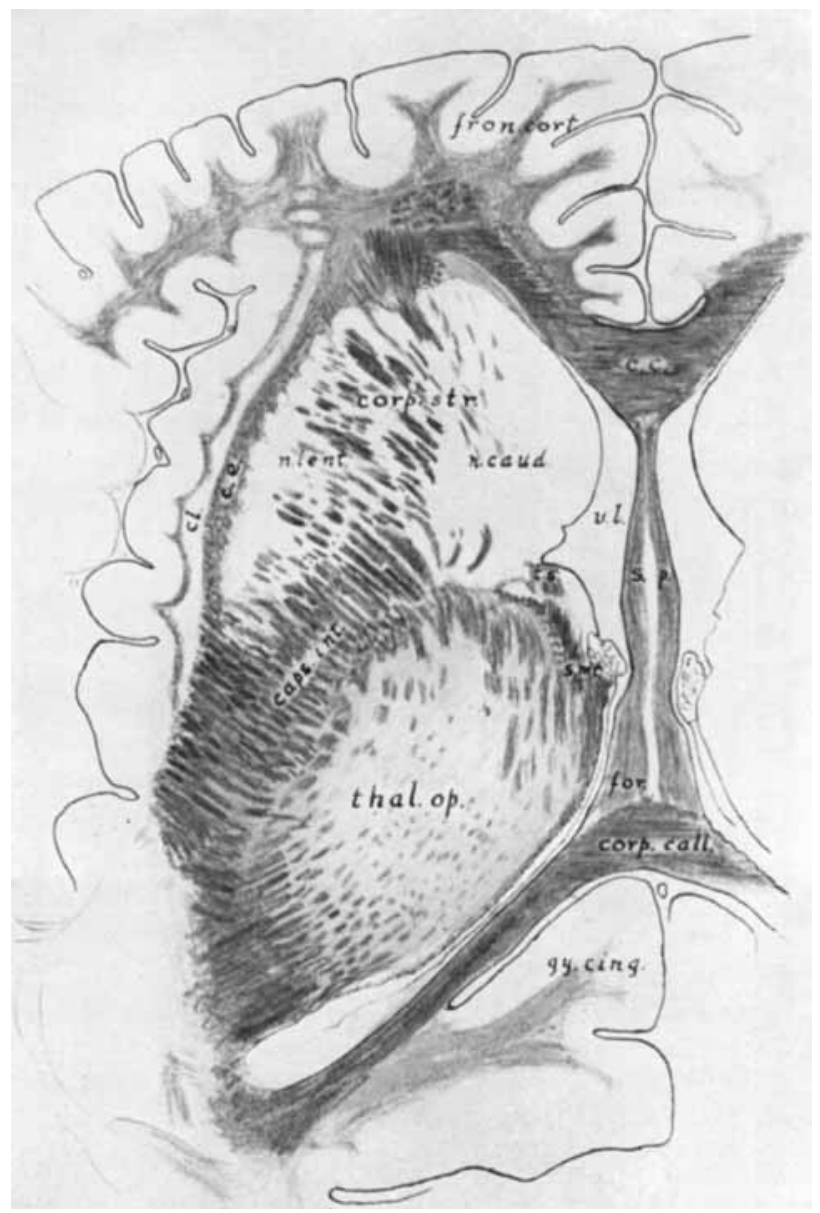

Fig. 14 Anterior portion of section 186, as shown in figure 6. Shows corpus callosum cut through twice (c.c., and corp.call.) and the thin intervening septum pellucidum $(s . p$.$) . This is thickened at one region by the fornix fibers (for.).$ The taenia semicircularis (t.s.) is in the groove at the junction of the corpus striatum (corp.str.) and the optic thalamus (thal.op.). On the margin of the latter are the fibers of the stria medullaris thalami (s.m.t.). $\times 2$.

c.e., external capsule; caps.int., internal capsule; $a$. , claustrum; fron.cort, frontal cortex; gy.cing., gyrus cinguli; n.caud., nucleus caudatus; n.lent., nucleus lentiformis; v.l., lateral ventricle. 
typical fornix fashion to the infundibular region, probably ending as usual in the nuclei of the corpora mamillaria.

The corpora mamillaria are very slightly developed, and do not show as typical rounded protuberances. However, immediately caudad of the posterior wall of the infundibulum is a median fissure (fig. 7, section 125), separating gray substance on either side which may be taken to represent the position of the two corpora mamillaria. In the series studied, there were practically no medullated fibers detected in these gray masses, but as the fornix fibers penetrate here, there must be some medullated fibers present.

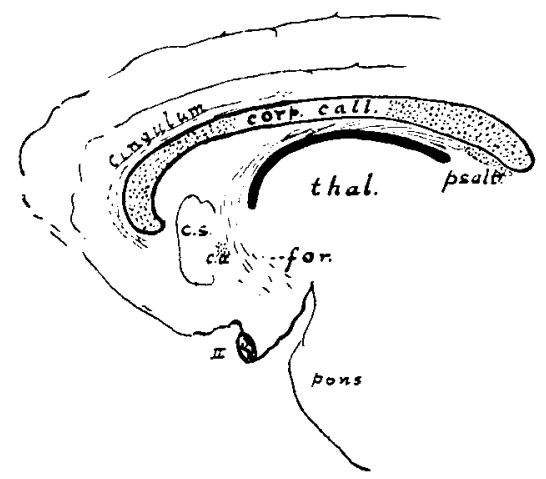

Fig. 15 Diagram of course of fornix fibers, reconstructed from several consecutive sagittal sections (after drawing sent by Professor Edinger).

$I I$, optic nerve; c.a., commissura anterior; c.s., corpus striatum; corp.call., corpus callosum; for., fornix.; psalt., psalterium; thal., thalamus.

The taenia thalami or stria medullaris thalami is present as a very thin flat bundle lying in the usual position at the mesial ridge of the thalamus opticus (fig. 14, section 186). Followed anteriorly it becomes thinner and thinner, and cannot definitely be traced to the region where it begins, viz., in the parolfactory and olfactory cortex. Followed posteriorly towards the ganglion habenulae the number of fibers apparently increases, being augmented probably by fibers orginating in the stratum zonale thalami. It is quite possible that the olfactory and parolfactory portions are entirely absent. 
The taenia semicircularis is shown in figures 12, 13, and 14, lying in the groove between the thalamus and the caudate nucleus, and also in figures 11 and 10 as it approaches its origin. Its fibers arise probably in the same region as that of the olfactory and parolfactory part of the taenia thalami but in these sections this was equally difficult to see. Its termination, the ganglion amygdalae, however, is well developed as illustrated in figure 9, section 143, which cuts its greatest expansion, and in figure 8, section 125 . It is situated at the extremity of the lateral ventricle in the temporal lobe, and lies partly in the ventricular floor (fig. 8). It shows its typical appearance, several medullated tracts traversing it and dividing it into smaller nuclei. The ganglion cells did not appear to be the same size in all the compartments. In section 143, figure 9, the nucleus amygdalae is directly continuous with the cortex of the temporal lobe, but more caudally (section 126, fig. 8), where the nucleus is smaller, there is a layer of cortical white matter forming a line of separation between the nucleus amygdalae and the cortex. Here it bulges in the floor of the lateral ventricle as it lies laterad of the hippocampus.

The anterior commissure (fig. 10, section 148) is present as a small transverse bundle, which soon disappears when followed away from the midline. It is probable that of the two parts which usually make up the anterior commissure, only the posterior part is present, and that the anterior part connecting the olfactory bulbs is entirely absent.

\section{SUMMARY}

In the adult dolphin, the olfactory bulbs and tracts are lacking, and that portion of the mesethmoid which corresponds to the cribriform plate of the ethmoid of the ordinary mammal is imperforate. Hence the dolphin is completely anosmatic in the sense of 'Turner's classification.

In addition to the lack of olfactory bulbs and tracts, the olfactory cortex of the basal surface of the frontal lobe is also wanting. In consequence of the recession of the cortex in this region, 
the corpus striatum of each side forms the surface as a convex oval area, the lobulc désert or désert olfactif of Broca. The parolfactory cortex is also much reduced, but at least some definite remains of it are seen. This is interesting in the light of Edinger's view, that the tuberculum olfactorium is not a part of the olfactory system, but is the end-station of tracts conveying impulses by way of the fifth nerve from specialized sensory structures in the snout region. 'To the sense, which this mechanism serves, he has given the name 'oral sense.'

Of the several connections of the olfactory and parolfactory cortical cells with the hippocampus, none were seen with certainty. It is possible that from the parolfactory cortex some fibers of the fasciculi parolfacto-hippocampo-septales (Zuckerkandl's bundle) are still retained, but as the origin as seen in these sections was doubtful, and as they normally pursue most of their course with the fornix fibers, one cannot decide definitely from the material at hand.

Of the other possible connections of the olfactory and parolfactory cortical cells, both the stria medullaris thalami (taenia thalami) and the taenia semicircularis are seen, as are their respective end-stations the ganglion habenulae and nucleus amygdalae. The latter are both quite definite.

The hippocampi are very degenerate small structures, and it is with difficulty that one sees the analogy with even the microsmatic type of hippocampus. The fissura hippocampi is shallow but definite and the subiculum is present. The gyrus dentatus does not appear as a separate structure, but there are cell-groups which evidently indicate the position of what remains of it. Connected with the hippocampus is the fimbria, seen as a slender band of fibers. True fornix fibers are seen, and can be followed in sagittal series of sections When I reported, in a preliminary way, at the meeting of the American Association of Anatomists in December, 1914 (Anatomical Record, vol. 9, no. 1) this was not known to me, but this information has been kindly transmitted by Professor Edinger since that time. The corpora mamillaria where the fornix fibers end are greatly reduced in size. The psalterium or commissura dorsalis, formed of cross- 
ing fibers between the two hippocampi is present very distinctly, but the anterior commissure is quite minute and it is probable that the olfactory portion is entirely lacking. The septum pellucidum is very thin.

Thus, this study of the brain of the dolphin shows that great atrophy of the hippocampal formation accompanies loss of the external olfactory structures, and that practically all the connecting tracts are likewise suppressed. The fact that both nucleus amygdalae and ganglion habenulae are present, though somewhat reduced, points to their having only a partial connection with the olfactory mechanism. There is a slight persistence of the parolfactory cortex, probably sufficient to give rise to, at least part of, the fibers of the stria medullaris thalami and taenia semicircularis.

\section{LITERATURE CITED}

Beccari, N. 1910 Il lobo paraolfattorio nei Mammiferi. Archivio di Anatomia e di Embriologia, vol. 9.

1911 La sostanza perforata anteriore e i suoi rapporti col rinencefalo nel cervello dell'uomo. Archivio di Anatomia e di Embriologia, vol. 10.

Bindewald, C. 1913 Das Rhinencephalon von Elephas indicus. Zool. Jahrb., vol. 35 , p. 563-582.

Broca, P. P. 1878 Le grand lobe limbique, et la scissure limbicue dans la série des Mammifères. Revue d'Anthropologie, $2^{\mathrm{e}}$ série, tome 1, p. $385-498$.

1879 Recherches sur les centres olfactifs. Revue d'Anthropologie, $2^{\mathrm{e}}$ série, t. 2, p. 385-455.

EdINGER, L. 1911 Vorlesungen über den Bau der Nervösen Zentralorgane. Bd. I, Leipzig.

Hatschex, R., and Schlesinger, H. 1902 Der Hirnstamm des Delphins. Arbeiten aus dem Neurologischen Institute an der Wiener Universität, Bd. 9, p. 1-117.

KÜkenthal, W., And Ziehes, T. 1889 Das CentraInervensystem der Cetaceen. Denk. d. med.-nat. Gesell. Jena, Bd. 3.

Peтtir, A. 1905 Description des encéphales. Resultats des Campagnes scientifiques de Prince de Monaco, fasc. 31.

Smith, G. Elliot 1902 Catalogue of the brain collection in the museum of the Royal College of Surgeons of England, vol. 2. 
Stanvixs, H. 1846 Cber den Bau des Delphin Gehirnes. Alshandlungen a. d. Gebiete der Naturwissenschaften in Hamburg, Bd. 1, p. 1-16.

Tiedemanv, F. 1826 Hirn des Delphins mit dem des Menschen vergleichen. Zeitsch. f. Physiologie, Bd. 2, p. 251-263.

Turner, W. 1890 The convolutions of the brain. Jour. Anat. and Phys., new series, vol. 1 .

Zuckerkande, E. 1887 Ueber das Riecheentrum. 8. Ueber die Bedeutung der bisher beschriebenen Rindentheile und über das Gehirn des Delphins, s. 87-109, Stuttgart.

Vildiger-Piersol 1912 Brain and spinal cord, Philadelphia. 